\title{
Piano-stool Ru(II)-benzene complexes bearing D/L-alanine derived chiral aroylthiourea ligands for asymmetric transfer hydrogenation of ketones in water
}

\author{
MANI MARY SHEEBA ${ }^{\mathrm{a}}$, NATTAMAI S P BHUVANESH ${ }^{\mathrm{b}}$ and RAMASAMY KARVEMBU ${ }^{\mathrm{a}, * \mathbb{D}}$ \\ ${ }^{a}$ Department of Chemistry, National Institute of Technology, Tiruchirappalli 620 015, Tamil Nadu, India \\ ${ }^{\mathrm{b}}$ Department of Chemistry, Texas A\&M University, College Station, TX 77842, USA \\ E-mail:kar@nitt.edu
}

MS received 14 March 2018; revised 25 September 2018; accepted 1 October 2018; published online 17 November 2018

\begin{abstract}
The new water soluble chiral $\mathrm{Ru}(\mathrm{II})$-benzene complexes of the type $\left[\mathrm{RuCl}_{2}\left(\eta^{6}-\mathrm{C}_{6} \mathrm{H}_{6}\right) \mathrm{L}\right]$ were obtained from the reactions between $\left[\mathrm{RuCl}_{2}\left(\eta^{6}-\mathrm{C}_{6} \mathrm{H}_{6}\right)\right]_{2}$ and the chiral aroylthiourea ligands (L) derived from unprotected D/L-alanine and characterized. The solid-state structure of representative complexes was confirmed by single crystal X-ray diffraction technique. The $\mathrm{Ru}(\mathrm{II})$-benzene complexes catalyzed the asymmetric transfer hydrogenation (ATH) of aromatic ketones to their enantiopure secondary alcohols. The reactions were carried out in the presence of formic acid-triethylamine mixture in water, and the product alcohols were obtained with excellent conversions (up to 99\%) and enantiomeric excesses (up to 99\%). The scope of the catalytic system was extended to various aromatic ketones. The catalytic activity of the present water-soluble Ru-benzene complexes toward enantioselective reduction of ketones was considerably higher than that of $p$-cymene analogues in water.
\end{abstract}

Keywords. Aroylthiourea; Ru-benzene; asymmetric transfer hydrogenation; aqueous medium.

\section{Introduction}

In organic synthesis, transfer hydrogenation is one of the most significant reduction reactions. The commonly used hydrogen donors for the reduction of ketones other than molecular hydrogen are 2-propanol/base, formic acid/triethylamine (azeotrope mixture) and formate salts. The use of formic acid/triethylamine is accompanied by the evolution of $\mathrm{CO}_{2}$ gas, which makes the reaction irreversible and has attracted the attention of chemists. ${ }^{1-3}$ In presence of water-soluble formic acid and its salts, transfer hydrogenation is more feasible in water which is undoubtedly a green reaction medium. ${ }^{4-6}$ However, compared to the most extensively studied aqueous-phase hydrogenation reactions, transfer hydrogenation in water has been investigated infrequently. 7,8

ATH reactions in aqueous media with $\mathrm{Ru}(\mathrm{II})$ complexes were initially concerned with organic-water biphasic systems, with the effort being focused on the design of water-soluble catalysts. ${ }^{9,10}$ However, the catalysts displayed activities and/or enantioselectivities lower than expected. The Noyori-Ikariya catalyst, derived in situ from $\left[\mathrm{RuCl}_{2}(p \text {-cymene })\right]_{2}$ and sulfonamide ligands, enabled efficient ATH in neat water. ${ }^{11}$ The reaction was considerably faster than in organic media and afforded excellent enantioselectivities. Thus, following the addition of 5 equivalents of HCOONa and acetophenone with a molar substrate to catalyst ratio $(\mathrm{S} / \mathrm{C})$ of 100 , the ketone was fully converted into $(R)$-1-phenylethanol in $95 \%$ ee after $1 \mathrm{~h}$ reaction time; in comparison, the reaction run in the $\mathrm{HCOOH}-\mathrm{NEt}_{3}$ azeotrope afforded a conversion of less than $2 \%$ in $1 \mathrm{~h}$, with full conversion requiring more than $10 \mathrm{~h}\left(97 \%\right.$ ee). ${ }^{12}$ Interestingly, $\beta$-aminoalcohol ligands were believed to be incompatible with formic acid as a reductant for ATH of ketones, ${ }^{3}$ the commercially available simple $\beta$-aminoalcohol ligands did catalyze the ATH of acetophenone by $\mathrm{HCOONa}$ or $\mathrm{HCOOH}-\mathrm{NEt}_{3}$ in water. ${ }^{13}$

Ruthenium complexes demonstrate a variety of useful characteristics, which include low redox potential, high electron transfer ability, high coordination ability to heteroatoms, Lewis acid acidity, unique reactivity of metallic species and intermediates such as oxo-

\footnotetext{
*For correspondence

Electronic supplementary material: The online version of this article (https://doi.org/10.1007/s12039-018-1566-5) contains supplementary material, which is available to authorized users.
} 
metals, metallacycles, and metal carbene complexes. $12,14,15 \mathrm{Ru}$-arene compounds are relatively inert towards substitution; arene moiety stabilizes and protects the metal center from rapid oxidation of $\mathrm{Ru}(\mathrm{II})$ to $\mathrm{Ru}(\mathrm{III}) .{ }^{16}$ Half-sandwich Ru-arene complexes containing asymmetric ligands have been used as effective catalysts in various asymmetric organic transformations. ${ }^{17}$ Therefore, a large number of novel, useful reactions have begun to be developed using catalytic amounts of ruthenium complexes.

The demand for enantiopure compounds is rapidly growing due to their prominence in the progress of several new biologically active compounds, such as pharmaceuticals and agrochemicals. ${ }^{18}$ For pharmaceuticals or pesticides, usually, only one enantiomer is responsible for the preferred biological activity, whereas the other is inactive or even causes dangerous side effects. Use of enantiomerically pure agrochemicals diminishes their effect on the environment. ${ }^{19}$ Likewise, production of many flavors, fragrances, chiral polymers, advanced materials with nonlinear optical properties, ferroelectric liquid crystals, etc., depends on the availability of chiral building blocks. ${ }^{20-24}$ Particularly, enantiomerically pure secondary alcohols are valuable resources for the synthesis of numerous pharmaceuticals. The need for enantiopure drugs has been improved in recent years and, hence, chiral alcohols are in demand. ${ }^{25}$ ATH of pro-chiral aromatic ketones is one of the impressive methods for the production of optically active secondary alcohols.

Here, we report the synthesis and characterization of new water-soluble $\mathrm{Ru}(\mathrm{II})$-benzene complexes of the type $\left[\mathrm{RuCl}_{2}\left(\eta^{6}-\mathrm{C}_{6} \mathrm{H}_{6}\right) \mathrm{L}\right](\mathbf{1}-\mathbf{6})$ where $\mathrm{L}=(R) /(S)-2$ (3-benzoylthioureido)propanoic acid (L1/L2), $(R) /(S)$ 2-(3-(thiophene-2-carbonyl)thioureido) propanoic acid (L3/L4) or $(R) /(S)$-2-(3-(furan-2-carbonyl)thioureido) propanoic acid (L5/L6). The catalytic performance of the complexes (1-6) was tested in ATH of aromatic, heterocyclic and bulky pro-chiral ketones to form corresponding enantiopure secondary alcohols in water medium.

\section{Experimental}

\subsection{Materials and methods}

The chiral aroylthiourea ligands and $\left[\mathrm{RuCl}_{2}\left(\eta^{6}-\mathrm{C}_{6} \mathrm{H}_{6}\right)\right]_{2}$ were prepared by following available procedures. ${ }^{26,27} \mathrm{UV}$ Visible spectra were recorded on a Shimadzu 2600 spectrophotometer, operating in the range of $200-800 \mathrm{~nm}$. FT-IR spectra in the range of $600-4000 \mathrm{~cm}^{-1}$ were recorded on a Nicolet iS5 FT-IR spectrophotometer as KBr pellets. CHNS analyses were performed using a Perkin Elmer 2400 series II elemental analyzer. NMR spectra were recorded on a Bruker $500 \mathrm{MHz}$ spectrometer. Melting points were determined on a Sigma melting point apparatus and are uncorrected. GCMS analyses for catalytic experiments were performed using a Shimadzu GCMS-QP 2010 Ultra gas chromatograph mass spectrometer with a Restek-5 capillary column. Enantiomeric excesses (ee) were determined using a Shimadzu HPLC instrument with a Daicel Chiralcel OB-H column. Specific rotation values were measured on a Rudolph Autopol IV polarimeter.

\subsection{Synthesis of the complexes (1-6)}

$\left[\mathrm{RuCl}_{2}\left(\eta^{6}-\mathrm{C}_{6} \mathrm{H}_{6}\right)\right]_{2}(110 \mathrm{mg}, 0.22 \mathrm{mmol})$ in toluene $(10 \mathrm{~mL})$ was added to the suspension of $(R) /(S)-2-(3-$ benzoylthioureido)propanoic acid $(111 \mathrm{mg}, 0.44 \mathrm{mmol})$ or $(R) /(S)$-2-(3-(thiophene-2-carbonyl)thioureido)propanoic acid $(113.6 \mathrm{mg}, 0.44 \mathrm{mmol})$ or $(R) /(S)$-2-(3-(furan-2carbonyl)thioureido)propanoic acid $(106.5 \mathrm{mg}, 0.44 \mathrm{mmol})$ in toluene $(15 \mathrm{~mL})$ and the resulting solution was stirred for $20 \mathrm{~h}$ at $27^{\circ} \mathrm{C}$. In the course of the reaction, an orange precipitate was formed; further, the addition of hexane gave an orange solid product. The product was collected by filtration, washed with hexane and dried in vacuo.

2.2a $\left[\mathrm{RuCl}_{2}\left(\eta^{6}-\mathrm{C}_{6} \mathrm{H}_{6}\right) L 1\right](\mathbf{1}): \quad$ Yield: $89 \mathrm{mg}, 88 \%$. M.p.: $178^{\circ} \mathrm{C}$. $[\alpha]_{D}^{27}:-72^{\circ}$. Anal. Calcd. for $\mathrm{C}_{17} \mathrm{H}_{18} \mathrm{Cl}_{2} \mathrm{~N}_{2} \mathrm{O}_{3}$ RuS : C, 40.64; H, 3.61; N, 5.58; S, 6.38. Found: C, 40.56; $\mathrm{H}, 3.54 ; \mathrm{N}, 5.47 ; \mathrm{S}, 6.29 .{ }^{1} \mathrm{H}$ NMR $\delta$, ppm $(500 \mathrm{MHz}$, DMSO- $\left.\mathrm{d}_{6}\right): 1.49\left(\mathrm{~d}, 3 \mathrm{H}, J=10 \mathrm{~Hz}, \mathrm{CH}_{3}\right), 4.81-4.87$ (m, $\left.1 \mathrm{H}, \mathrm{C}^{*} \mathrm{HMe}\right), 5.96\left(\mathrm{~s}, 6 \mathrm{H}, \mathrm{C}_{6} \mathrm{H}_{6}\right), 7.50-8.30(\mathrm{~m}, 5 \mathrm{H}$, aromatic protons), $11.29(\mathrm{~d}, 1 \mathrm{H}, J=10 \mathrm{~Hz}, \mathrm{C}=\mathrm{S}$ attached $\mathrm{N}-\mathrm{H}), 11.49(\mathrm{~s}, 1 \mathrm{H}, \mathrm{C}=\mathrm{O}$ and $\mathrm{C}=\mathrm{S}$ attached $\mathrm{N}-\mathrm{H}), 13.20(\mathrm{bs}$, $1 \mathrm{H}, \mathrm{COOH}) \mathrm{ppm} .{ }^{13} \mathrm{C}$ NMR $\delta, \operatorname{ppm}\left(125 \mathrm{MHz}, \mathrm{DMSO}-\mathrm{d}_{6}\right)$ : $17.1\left(\mathrm{CH}_{3}\right), 53.0$ (asymmetric carbon), $87.6\left(\mathrm{C}_{6} \mathrm{H}_{6}\right), 128.4$, 128.5, 132.0, 133.0 (aromatic carbons), $168.4(\mathrm{C}=\mathrm{O}), 172.8$ $(\mathrm{C}=\mathrm{S}), 179.8(\mathrm{COOH}) \mathrm{ppm}$. FT-IR $\left(\mathrm{KBr}, \mathrm{cm}^{-1}\right): 3343(\mathrm{~m}$, $v($ amide $\mathrm{N}-\mathrm{H})), 3166(\mathrm{~s}, v($ thiourea $\mathrm{N}-\mathrm{H})), 1684(\mathrm{~s}, v(\mathrm{C}=\mathrm{O}))$, $1751(\mathrm{~s}, v(\mathrm{COOH})), 1182(\mathrm{~s}, v(\mathrm{C}=\mathrm{S}))$. UV-Vis $\left[\mathrm{CHCl}_{3}\right.$; $\left.\lambda, \mathrm{nm}\left(\varepsilon, \mathrm{dm}^{3} \mathrm{~mol}^{-1} \mathrm{~cm}^{-1}\right)\right]: 442$ (7836), 320 (40167), 253 (171032).

2.2b $\left[\mathrm{RuCl}_{2}\left(\eta^{6}-\mathrm{C}_{6} \mathrm{H}_{6}\right) L 2\right](2): \quad$ Yield: $91 \mathrm{mg}, 90 \%$. M.p.: $178^{\circ} \mathrm{C} .[\alpha]_{D}^{27}:+74^{\circ}$. Anal. Calcd. for $\mathrm{C}_{17} \mathrm{H}_{18} \mathrm{Cl}_{2} \mathrm{~N}_{2} \mathrm{O}_{3}$ RuS: C, 40.64; H, 3.61; N, 5.58; S, 6.38. Found: C, 40.54; $\mathrm{H}, 3.55 ; \mathrm{N}, 5.49 ; \mathrm{S}, 6.28 .{ }^{1} \mathrm{H}$ NMR $\delta, \mathrm{ppm}(500 \mathrm{MHz}$, DMSO-d $\left._{6}\right): 1.49\left(\mathrm{~d}, 3 \mathrm{H}, J=5 \mathrm{~Hz}, \mathrm{CH}_{3}\right), 4.83-4.86(\mathrm{~m}$, $1 \mathrm{H}, \mathrm{C} * \mathrm{HMe}$ ), $5.97\left(\mathrm{~s}, 6 \mathrm{H}, \mathrm{C}_{6} \mathrm{H}_{6}\right), 7.51-7.94(\mathrm{~m}, 5 \mathrm{H}$, aromatic protons), $11.30(\mathrm{~d}, 1 \mathrm{H}, J=10 \mathrm{~Hz}, \mathrm{C}=\mathrm{S}$ attached $\mathrm{N}-\mathrm{H}), 11.50(\mathrm{~s}, 1 \mathrm{H}, \mathrm{C}=\mathrm{O}$ and $\mathrm{C}=\mathrm{S}$ attached $\mathrm{N}-\mathrm{H}), 13.23$ (bs, $1 \mathrm{H}, \mathrm{COOH}) \mathrm{ppm} .{ }^{13} \mathrm{C}$ NMR $\delta$, ppm $\left(125 \mathrm{MHz}, \mathrm{DMSO}-\mathrm{d}_{6}\right)$ : $17.1\left(\mathrm{CH}_{3}\right), 53.0$ (asymmetric carbon), $87.6\left(\mathrm{C}_{6} \mathrm{H}_{6}\right), 128.4$, 128.5, 132.0, 133.0 (aromatic carbons), $168.4(\mathrm{C}=\mathrm{O}), 172.8$ $(\mathrm{C}=\mathrm{S}), 179.8(\mathrm{COOH}) \mathrm{ppm}$. FT-IR $\left(\mathrm{KBr}, \mathrm{cm}^{-1}\right): 3222(\mathrm{~m}$; $v($ amide $\mathrm{N}-\mathrm{H})), 3181(\mathrm{~s} ; v($ thiourea $\mathrm{N}-\mathrm{H})), 1674(\mathrm{~s} ; v(\mathrm{C}=\mathrm{O}))$, $1747(\mathrm{~s} ; v(\mathrm{COOH})), 1195(\mathrm{~s} ; v(\mathrm{C}=\mathrm{S}))$. UV-Vis $\left[\mathrm{CHCl}_{3} ; \lambda\right.$, 
$\left.\mathrm{nm}\left(\varepsilon, d m^{3} \mathrm{~mol}^{-1} \mathrm{~cm}^{-1}\right)\right]: 442$ (10527), 320 (31589), 254 (116862).

2.2c $\left[\mathrm{RuCl}_{2}\left(\eta^{6}-\mathrm{C}_{6} \mathrm{H}_{6}\right) L 3\right](3)$ : Yield: $88 \mathrm{mg}, 86 \%$. M.p.: $182{ }^{\circ} \mathrm{C} .[\alpha]_{D}^{27}:+71^{\circ}$. Anal. Calcd. for $\mathrm{C}_{15} \mathrm{H}_{16} \mathrm{Cl}_{2} \mathrm{~N}_{2} \mathrm{O}_{3}$ $\mathrm{RuS}_{2}$ : C, 35.44; H, 3.17; N, 5.51; S, 12.61. Found: C, 35.36; $\mathrm{H}, 3.06$; N, 5.43; S, 12.49. ${ }^{1} \mathrm{H}$ NMR $\delta, p p m(500 \mathrm{MHz}$, DMSO- $\left.\mathrm{d}_{6}\right): 1.47\left(\mathrm{~d}, 3 \mathrm{H}, J=5 \mathrm{~Hz}, \mathrm{CH}_{3}\right), 4.79-4.85$ (m, 1H, C*HMe), $5.97\left(\mathrm{~s}, 6 \mathrm{H}, \mathrm{C}_{6} \mathrm{H}_{6}\right), 7.22-8.35(\mathrm{~m}, 3 \mathrm{H}$, aromatic protons), $11.15(\mathrm{~d}, 1 \mathrm{H}, J=5 \mathrm{~Hz}, \mathrm{C}=\mathrm{S}$ attached $\mathrm{N}$ $\mathrm{H}), 11.56(\mathrm{~s}, 1 \mathrm{H}, \mathrm{C}=\mathrm{O}$ and $\mathrm{C}=\mathrm{S}$ attached $\mathrm{N}-\mathrm{H}), 13.20(\mathrm{bs}$, $1 \mathrm{H}, \mathrm{COOH}) \mathrm{ppm} .{ }^{13} \mathrm{C}$ NMR $\delta$, ppm $\left(125 \mathrm{MHz}, \mathrm{DMSO}-\mathrm{d}_{6}\right)$ : $17.1\left(\mathrm{CH}_{3}\right), 53.0$ (asymmetric carbon), $87.6\left(\mathrm{C}_{6} \mathrm{H}_{6}\right), 128.6$, 132.5, 135.2, 136.5 (aromatic carbons), $162.2(\mathrm{C}=\mathrm{O}), 172.8$ $(\mathrm{C}=\mathrm{S}), 179.5(\mathrm{COOH}) \mathrm{ppm}$. FT-IR $\left(\mathrm{KBr}, \mathrm{cm}^{-1}\right): 3348(\mathrm{~m}$; $v($ amide $\mathrm{N}-\mathrm{H})), 3211(\mathrm{~s} ; v($ thiourea $\mathrm{N}-\mathrm{H})), 1697(\mathrm{~s} ; v(\mathrm{C}=\mathrm{O}))$, $1725(\mathrm{~s} ; v(\mathrm{COOH})), 1191(\mathrm{~s} ; v(\mathrm{C}=\mathrm{S}))$. UV-Vis $\left[\mathrm{CHCl}_{3} ; \lambda\right.$, $\left.\mathrm{nm}\left(\varepsilon, \mathrm{dm}^{3} \mathrm{~mol}^{-1} \mathrm{~cm}^{-1}\right)\right]$ : 442 (11483), 330 (70000), 296 (133161), 253 (177806).

2.2d $\left[\mathrm{RuCl}_{2}\left(\eta^{6}-\mathrm{C}_{6} \mathrm{H}_{6}\right) L 4\right](4): \quad$ Yield: $90 \mathrm{mg}, 88 \%$. M.p.: $183^{\circ} \mathrm{C} .[\alpha]_{\mathrm{D}}^{27}:-76^{\circ}$. Anal. Calcd. for $\mathrm{C}_{15} \mathrm{H}_{16} \mathrm{Cl}_{2} \mathrm{~N}_{2} \mathrm{O}_{3}$ $\mathrm{RuS}_{2}$ : C, 35.44; H, 3.17; N, 5.51; S, 12.61. Found: C, 35.38; $\mathrm{H}, 3.07$; N, $5.45 \mathrm{~S}, 12.52 .{ }^{1} \mathrm{H}$ NMR $\delta$, ppm $(500 \mathrm{MHz}$, DMSO- $\left._{6}\right): 1.48\left(\mathrm{~d}, 3 \mathrm{H}, J=10 \mathrm{~Hz}, \mathrm{CH}_{3}\right), 4.80-4.85$ (m, 1H, C* $\mathrm{HMe}), 5.97\left(\mathrm{~s}, 6 \mathrm{H}, \mathrm{C}_{6} \mathrm{H}_{6}\right), 7.23-8.36(\mathrm{~m}, 3 \mathrm{H}$, aromatic protons), $11.15(\mathrm{~d}, 1 \mathrm{H}, J=5 \mathrm{~Hz}, \mathrm{C}=\mathrm{S}$ attached $\mathrm{N}-\mathrm{H}), 11.57(\mathrm{~s}, 1 \mathrm{H}, \mathrm{C}=\mathrm{O}$ and $\mathrm{C}=\mathrm{S}$ attached $\mathrm{N}-\mathrm{H}), 13.21$ (bs, $1 \mathrm{H}, \mathrm{COOH}) \mathrm{ppm} .{ }^{13} \mathrm{C}$ NMR $\delta$, ppm $(125 \mathrm{MHz}$, DMSO-d 6 ): $17.1\left(\mathrm{CH}_{3}\right), 53.0$ (asymmetric carbon), $87.6\left(\mathrm{C}_{6} \mathrm{H}_{6}\right), 128.6$, 132.5, 135.2, 136.5 (aromatic carbons), $162.2(\mathrm{C}=\mathrm{O}), 172.8$ $(\mathrm{C}=\mathrm{S}), 179.5(\mathrm{COOH}) \mathrm{ppm}$. FT-IR $\left(\mathrm{KBr}, \mathrm{cm}^{-1}\right): 3347(\mathrm{~m}$; $v($ amide $\mathrm{N}-\mathrm{H})), 3207(\mathrm{~s} ; v($ thiourea $\mathrm{N}-\mathrm{H})), 1697(\mathrm{~s} ; v(\mathrm{C}=\mathrm{O}))$, $1725(\mathrm{~s} ; \mathrm{v}(\mathrm{COOH})), 1195(\mathrm{~s} ; \mathrm{v}(\mathrm{C}=\mathrm{S}))$. UV-Vis $\left[\mathrm{CHCl}_{3}\right.$; $\left.\lambda, \mathrm{nm}\left(\varepsilon, \mathrm{dm}^{3} \mathrm{~mol}^{-1} \mathrm{~cm}^{-1}\right)\right]: 446$ (9196), 330 (65026), 294 (114225), 253 (154844).

2.2e $\quad\left[\mathrm{RuCl}_{2}\left(\eta^{6}-\mathrm{C}_{6} \mathrm{H}_{6}\right) L 5\right](\mathbf{5}): \quad$ Yield: $89 \mathrm{mg}, 91 \%$. M.p.: $163^{\circ} \mathrm{C}$. $[\alpha]_{D}^{27}:-48^{\circ}$. Anal. Calcd. for $\mathrm{C}_{19} \mathrm{H}_{30} \mathrm{Cl}_{2} \mathrm{~N}_{2} \mathrm{O}_{4}$ RuS: C, 41.16; H, 5.45; N, 5.05; S, 5.78. Found: C, 41.05; $\mathrm{H}, 5.34 ; \mathrm{N}, 4.97 ; \mathrm{S}, 5.69 .{ }^{1} \mathrm{H}$ NMR $\delta$, ppm $(500 \mathrm{MHz}$, DMSO-d $_{6}$ ): $1.47\left(\mathrm{~d}, 3 \mathrm{H}, J=5 \mathrm{~Hz}, \mathrm{CH}_{3}\right), 3.39(\mathrm{bs}, \mathrm{COOH}$, $\mathrm{H}_{2} \mathrm{O}$ and $\mathrm{COOCH}_{3}$ merged), 4.80-4.83 (m, 1H, C*HMe), $5.97\left(\mathrm{~s}, 6 \mathrm{H}, \mathrm{C}_{6} \mathrm{H}_{6}\right), 6.73-8.05(\mathrm{~m}, 3 \mathrm{H}$, aromatic protons), $11.04(\mathrm{~d}, 1 \mathrm{H}, J=5 \mathrm{~Hz}, \mathrm{C}=\mathrm{S}$ attached $\mathrm{N}-\mathrm{H}), 11.23(\mathrm{~s}$, $1 \mathrm{H}, \mathrm{C}=\mathrm{O}$ and $\mathrm{C}=\mathrm{S}$ attached $\mathrm{N}-\mathrm{H}) .{ }^{13} \mathrm{C} \mathrm{NMR} \delta$, ppm $(125$ $\left.\mathrm{MHz}, \mathrm{DMSO}-\mathrm{d}_{6}\right)$ : $17.1\left(\mathrm{CH}_{3}\right), 53.0$ (asymmetric carbon), 87.6 $\left(\mathrm{C}_{6} \mathrm{H}_{6}\right), 112.5,118.5,144.5,148.3$ (aromatic carbons), $157.7(\mathrm{C}=\mathrm{O}), 172.7(\mathrm{C}=\mathrm{S}), 179.4(\mathrm{COOH}) \mathrm{ppm}$. FT-IR $(\mathrm{KBr}$, $\left.\mathrm{cm}^{-1}\right): 3211(\mathrm{~m} ; v($ amide $\mathrm{N}-\mathrm{H})), 3116(\mathrm{~s} ; \mathrm{v}($ thiourea $\mathrm{N}-\mathrm{H})$ ), $1665(\mathrm{~s} ; v(\mathrm{C}=\mathrm{O})), 1701(\mathrm{~s} ; v(\mathrm{COOH})), 1201(\mathrm{~s} ; v(\mathrm{C}=\mathrm{S}))$. UVVis $\left[\mathrm{CHCl}_{3} ; \lambda, \mathrm{nm}\left(\varepsilon, \mathrm{dm}^{3} \mathrm{~mol}^{-1} \mathrm{~cm}^{-1}\right)\right]: 449$ (7571), 323 (41360), 284 (114398), 253 (97812).

2.2f $\left[\mathrm{RuCl}_{2}\left(\eta^{6}-\mathrm{C}_{6} \mathrm{H}_{6}\right) L 6\right](6): \quad$ Yield: $86 \mathrm{mg}, 88 \%$. M.p.: $164^{\circ} \mathrm{C}$. $[\alpha]_{D}^{27}:+45^{\circ}$. Anal. Calcd. for $\mathrm{C}_{19} \mathrm{H}_{30} \mathrm{Cl}_{2} \mathrm{~N}_{2} \mathrm{O}_{4}$ RuS: C, 41.16; H, 5.45; N, 5.05; S, 5.78. Found: C, 41.07;
$\mathrm{H}, 5.35 ; \mathrm{N}, 4.96 ; \mathrm{S}, 5.67 .{ }^{1} \mathrm{H}$ NMR $\delta$, ppm $(500 \mathrm{MHz}$, DMSO-d 6 ): $1.47\left(\mathrm{~d}, 3 \mathrm{H}, J=5 \mathrm{~Hz}, \mathrm{CH}_{3}\right), 4.79-4.84$ $(\mathrm{m}, 1 \mathrm{H}, \mathrm{C} * \mathrm{HMe}), 5.97\left(\mathrm{~s}, 6 \mathrm{H}, \mathrm{C}_{6} \mathrm{H}_{6}\right), 6.73-8.05(\mathrm{~m}, 3 \mathrm{H}$, aromatic protons), $11.04(\mathrm{~d}, 1 \mathrm{H}, J=10 \mathrm{~Hz}, \mathrm{C}=\mathrm{S}$ attached $\mathrm{N}-\mathrm{H}), 11.23$ (s, 1H, C=O and $\mathrm{C}=\mathrm{S}$ attached $\mathrm{N}-\mathrm{H}), 13.20$ (bs, $1 \mathrm{H}, \mathrm{COOH}) \mathrm{ppm} .{ }^{13} \mathrm{C}$ NMR $\delta, \operatorname{ppm}\left(125 \mathrm{MHz}, \mathrm{DMSO}-\mathrm{d}_{6}\right)$ : $17.1\left(\mathrm{CH}_{3}\right), 53.0$ (asymmetric carbon), $87.6\left(\mathrm{C}_{6} \mathrm{H}_{6}\right), 112.5$, 118.5, 144.5, 148.3 (aromatic carbons), $157.8(\mathrm{C}=\mathrm{O}), 172.8$ $(\mathrm{C}=\mathrm{S}), 179.4(\mathrm{COOH}) \mathrm{ppm}$. FT-IR $\left(\mathrm{KBr}, \mathrm{cm}^{-1}\right): 3222(\mathrm{~m}$; $v($ amide $\mathrm{N}-\mathrm{H})), 3157(\mathrm{~s} ; v($ thiourea $\mathrm{N}-\mathrm{H})), 1681(\mathrm{~s} ; \nu(\mathrm{C}=\mathrm{O}))$, $1740(\mathrm{~s} ; \nu(\mathrm{COOH})), 1196(\mathrm{~s} ; \nu(\mathrm{C}=\mathrm{S}))$. UV-Vis $\left[\mathrm{CHCl}_{3} ; \lambda, \mathrm{nm}\right.$ $\left.\left(\varepsilon, \mathrm{dm}^{3} \mathrm{~mol}^{-1} \mathrm{~cm}^{-1}\right)\right]: 445$ (5354), 324 (29193), 281 (88548), 251 (71193).

\section{$2.3 X$-ray structure analysis}

The details of data collection are given in Table S1 (Supplementary Information). The crystal was placed in a cold nitrogen stream maintained at $150 \mathrm{~K}$. A BRUKER APEX2 X-ray (three-circle) diffractometer was employed for crystal screening, unit cell determination and data collection.The goniometer was controlled using the APEX2 software suite, v2008-6.0. ${ }^{28}$ Integrated intensity information for each reflection was obtained by the reduction of the data frames with the program APEX2. ${ }^{28}$ The absorption correction program SADABS ${ }^{29}$ was employed to correct the data for absorption effects. A solution was obtained readily using XT/XS in APEX2. ${ }^{28,30,31}$ Hydrogen atoms were placed in idealized positions and were set riding on the respective parent atoms. All the non-hydrogen atoms were refined with anisotropic thermal parameters. The absence of additional symmetry and voids were confirmed using PLATON (ADDSYM). ${ }^{32}$ The structure was refined (weighted leastsquares refinement on $F^{2}$ ) to convergence. ${ }^{30,31,33}$ Olex2 was employed for the final data presentation and structure plots. ${ }^{33}$

\subsection{Procedure for ATH of ketones in water}

$\mathrm{HCOOH}-\mathrm{Et}_{3} \mathrm{~N}$ (molar ratio 1.0:5.1) mixture was added to the $\mathrm{Ru}(\mathrm{II})$-benzene complex $(0.005 \mathrm{mmol})$ in water $(0.5 \mathrm{~mL})$. Subsequently ketone $(1 \mathrm{mmol})$ was introduced into the mixture and stirred at $60^{\circ} \mathrm{C}$ for $15 \mathrm{~h}$. Then, the reaction mixture was cooled to room temperature, quenched with ice and extracted with dichloromethane. The extracts were dried over $\mathrm{Na}_{2} \mathrm{SO}_{4}$, filtered, then passed through a silica gel short column with $N$-hexane-ethyl acetate $(1: 1)$ eluent to remove the Ru catalyst.

\section{Results and Discussion}

\subsection{Synthesis of the Ru(II)-benzene complexes}

The air-stable, water-soluble half-sandwich $\mathrm{Ru}(\mathrm{II})$ complexes (1-6) were prepared in good yields from the reactions between $\left[\mathrm{RuCl}_{2}\left(\eta^{6}-\mathrm{C}_{6} \mathrm{H}_{6}\right)\right]_{2}$ and unprotected 


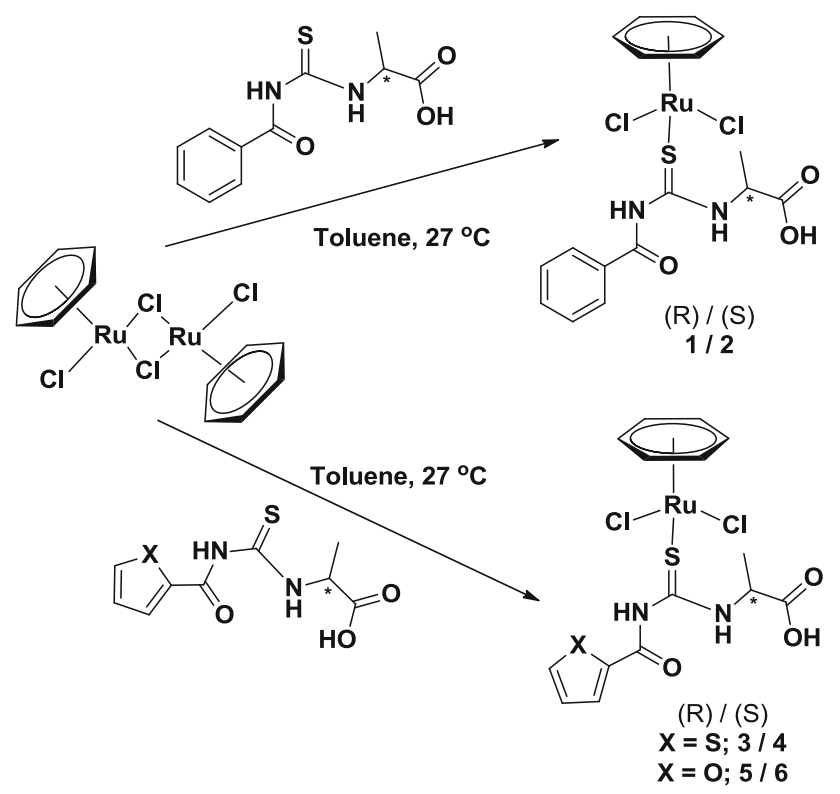

Scheme 1. Synthesis of the complexes (1-6).

D/L-alanine derived chiral aroylthiourea ligands (L1L6) (Scheme 1). The new complexes were soluble in water, DMSO, DMF, $\mathrm{CH}_{3} \mathrm{CN}, \mathrm{CHCl}_{3}, \mathrm{CH}_{2} \mathrm{Cl}_{2}, \mathrm{CH}_{3} \mathrm{OH}$ and $\mathrm{C}_{2} \mathrm{H}_{5} \mathrm{OH}$. The $\mathrm{Ru}$ (II)-benzene complexes were characterized by elemental analyses, and UV-Visible, FT-IR, ${ }^{1} \mathrm{H}$ NMR and ${ }^{13} \mathrm{C}$ NMR spectral studies. The optical rotation values of the compounds were obtained from polarimetric analyses. The molecular structure of the $\mathrm{Ru}$ (II) complexes $(\mathbf{1}, \mathbf{3}$ and $\mathbf{5}$ ) was confirmed by single crystal X-ray diffraction study.

\subsection{Spectroscopic characterization of the complexes}

The absorption bands observed in the UV-Visible spectra of the complexes in the regions 442-449 and $320-330 \mathrm{~nm}$ were assigned to the $\mathrm{d}-\mathrm{d}$ and ligand to metal charge transfer transitions respectively. The FT-IR spectra of the ligands showed bands in the regions 3385$3254 \mathrm{~cm}^{-1}$ for amide $\mathrm{N}-\mathrm{H}, 3157-3106 \mathrm{~cm}^{-1}$ for thiourea $\mathrm{N}-\mathrm{H}, 1659-1679 \mathrm{~cm}^{-1}$ for $\mathrm{C}=\mathrm{O}$ and $1258-1284 \mathrm{~cm}^{-1}$ for $\mathrm{C}=\mathrm{S}$. On complexation, the $v(\mathrm{C}=\mathrm{S})$ of the ligands decreased to $1182-1201 \mathrm{~cm}^{-1}$ while the other frequencies were unaltered, which confirmed the monodentate sulfur only coordination mode of the aroylthiourea ligands. ${ }^{34}$

In the ${ }^{1} \mathrm{H}$ NMR spectra of the complexes (1-6), the carbonyl and thiocarbonyl attached $\mathrm{N}-\mathrm{H}$, and thiocarbonyl attached $\mathrm{N}-\mathrm{H}$ protons were observed around 11.04-11.30 ppm (doublet) and 11.23-11.57 ppm (singlet) respectively. The signals at 5.96-5.97 ppm specified the presence of benzene moiety in the complexes. ${ }^{35,36}$ All other chemical shift values of the complexes were comparable to those of the free ligands. The ${ }^{13} \mathrm{C}$ NMR chemical shift values did not change significantly upon coordination of the ligands to $\mathrm{Ru}(\mathrm{II})$. A new signal observed at $87.6 \mathrm{ppm}$ confirmed the presence of benzene in all the complexes.

\subsection{Crystal structure of the complexes}

The single crystal X-ray structure of complexes 1, 3 and $\mathbf{5}$ are shown in Figures 1-3 respectively. Complex 1 crystallized in the chiral monoclinic crystal system with the space group $P 2_{1}$, and complexes $\mathbf{3}$ and $\mathbf{5}$ crystallized in the chiral orthorhombic system with the space group $P 2{ }_{1} 2_{1} 2_{1}$. The absolute configuration of complexes 1, $\mathbf{3}$ and $\mathbf{5}$ was clearly determined directly from the X-ray data. The presence of a water molecule(s) in the lattice stabilized the structures. Elongated thermal ellipsoids and a $\mathrm{Q}$ peak $\left(\sim 2 \mathrm{e}^{-} / \AA^{3}\right)$ suggested a disorder of the $\mathrm{COOH}$ and $\mathrm{COOCH}_{3}$ groups (both present) in $\mathbf{5}$. The disorder was successfully modeled with an occupancy ratio of 0.58:0.42. The occupancy of $\mathrm{O} 1 \mathrm{~W}$ also refined close to 0.58 . For the final refinement, the occupancies were fixed. The values of bond lengths $\mathrm{Ru}(1)-\mathrm{S}(1), \mathrm{Ru}(1)-\mathrm{Cl}(1)$ and $\mathrm{Ru}(1)-\mathrm{Cl}(2)$, and bond angles $\mathrm{S}(1)-\mathrm{Ru}(1)-\mathrm{Cl}(1), \mathrm{S}(1)-\mathrm{Ru}(1)-\mathrm{Cl}(1)$, $\mathrm{Cl}(2)-\mathrm{Ru}(1)-\mathrm{Cl}(1)$ and $\mathrm{C}(1)-\mathrm{S}(1)-\mathrm{Ru}(1)$ were comparable with those provided in the previous report. ${ }^{36}$ The monodentate sulfur only coordination of the aroylthiourea ligands was explicitly seen in the complexes. In the complexes, Ru ion exhibited half-sandwich "3legged piano-stool" coordination geometry.

\subsection{Asymmetric transfer hydrogenation of ketones}

Catalytic activity of the water soluble $\mathrm{Ru}(\mathrm{II})$-benzene complexes (1-6) was studied for the asymmetric transfer hydrogenation of ketones to provide their respective chiral alcohols in water medium with the use of formic acid-triethylamine mixture at $60{ }^{\circ} \mathrm{C}$. The complexes performed as effective catalysts to show up to $99 \%$ conversion and $99 \%$ ee after $15 \mathrm{~h}$ (Table 1 ).

ATH of acetophenone was carried out with enhanced efficiency using the $\mathrm{Ru}(\mathrm{II})$-benzene complexes as catalysts. The efficacy of the present Ru-benzene catalytic system was compared with that of already reported catalysts based on $\left[\mathrm{RuCl}_{2}\left(\eta^{6} \text {-benzene }\right)\right]_{2}$, particularly with respect to ATH of acetophenone to 1-phenylethanol in water medium (Table 1, entries 1-6). The complexes derived from $(1 R, 2 R)$-diaminocyclohexane and $\left[\mathrm{RuCl}_{2}\left(\eta^{6} \text {-benzene }\right)\right]_{2}$ were used as catalysts with HCOONa in water, which offered $94 \%$ conversion and $54 \%$ ee $^{37}$ The optical purity of 1-phenylethanol is very much less compared to that obtained from the 
Table 1. Asymmetric transfer hydrogenation of ketones catalyzed by the $\mathrm{Ru}(\mathrm{II})$ complexes (1-6) ${ }^{\mathrm{a}}$.

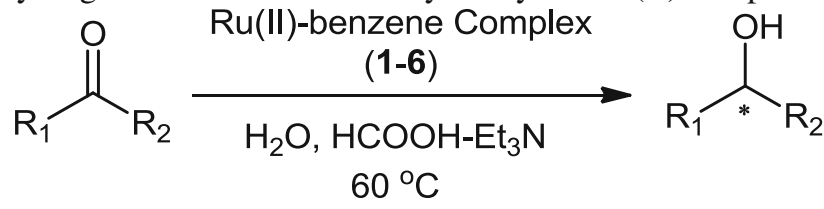

\begin{tabular}{|c|c|c|c|c|c|c|}
\hline Entry & Catalyst & Substrate & Product & Conversion $^{b}(\%)$ & $\mathrm{ee}^{\mathrm{c}}(\%) /$ Configuration ${ }^{\mathrm{d}}$ & $\mathrm{TON}^{\mathrm{e}}$ \\
\hline 1 & 1 & & & 99 & $74 / S$ & 198 \\
\hline 2 & 2 & O & $\mathrm{OH}$ & 54 & $96 / S$ & 108 \\
\hline 3 & 3 & & & 99 & $64 / R$ & 198 \\
\hline 4 & 4 & & & 99 & $99 / S$ & 198 \\
\hline 5 & 5 & & & 99 & $99 / S$ & 198 \\
\hline 6 & 6 & & & 61 & $99 / S$ & 122 \\
\hline 7 & 1 & & & 71 & $99 / R$ & 142 \\
\hline 8 & 2 & $\mathrm{O}$ & $\mathrm{OH}$ & 78 & $89 / R$ & 156 \\
\hline 9 & 3 & & & 84 & $87 / R$ & 168 \\
\hline 10 & 4 & & & 62 & $97 / R$ & 124 \\
\hline 11 & 5 & & & 81 & $92 / R$ & 162 \\
\hline 12 & 6 & & & 63 & $72 / R$ & 126 \\
\hline 13 & 1 & & & 88 & $65 / R$ & 176 \\
\hline 14 & 2 & & & 94 & $82 / R$ & 188 \\
\hline 15 & 3 & & & 90 & $94 / R$ & 188 \\
\hline 16 & 4 & & & 71 & $50 / R$ & 142 \\
\hline 17 & 5 & & & 92 & $74 / R$ & 184 \\
\hline 18 & 6 & & & 86 & $94 / R$ & 172 \\
\hline 19 & 1 & & & 98 & $86 / R$ & 196 \\
\hline 20 & 2 & 0 & & 98 & $84 / R$ & 196 \\
\hline 21 & 3 & & & 97 & $88 / S$ & 194 \\
\hline 22 & 4 & & & 86 & $58 / R$ & 172 \\
\hline 23 & 5 & & & 97 & $97 / S$ & 194 \\
\hline 24 & 6 & & & 98 & $62 / R$ & 196 \\
\hline 25 & 1 & & & 78 & $45 / S$ & 156 \\
\hline 26 & 2 & & & 60 & $98 / R$ & 120 \\
\hline 27 & 3 & & & 70 & $90 / R$ & 140 \\
\hline 28 & 4 & & & 78 & $78 / R$ & 156 \\
\hline 29 & 5 & & & 85 & $80 / R$ & 190 \\
\hline 30 & 6 & & & 54 & $82 / S$ & 108 \\
\hline
\end{tabular}

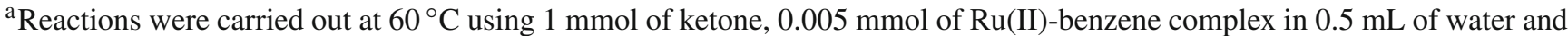
$\mathrm{HCOOH}: \mathrm{Et}_{3} \mathrm{~N}$ (molar ratio 1.0:5.1) for $15 \mathrm{~h}$. ${ }^{\mathrm{b}}$ The conversion was determined by GC-MS. ${ }^{\mathrm{c}}$ ee was calculated by chiral HPLC analysis. ${ }^{\mathrm{d}}$ Absolute configuration was determined from the optical rotation values. ${ }^{\mathrm{e}} \mathrm{TON}=$ moles of the product formed $/ \mathrm{moles}$ of the catalyst used.

present catalytic system. $\left[\mathrm{RuCl}_{2}\left(\eta^{6} \text {-benzene) }\right]_{2}\right.$ along with bulky roofed cis-diamine catalyzed the ATH of acetophenone to 1-phenylethanol in water with very good conversion (98\%) and ee (93\%) using $\mathrm{HCOOH}-\mathrm{NEt}_{3}$ mixture as a hydrogen donor, ${ }^{38}$ which was comparable with the present results. Pseudo-dipeptide on combination with $\left[\mathrm{RuCl}_{2}\left(\eta^{6} \text {-benzene }\right)\right]_{2}$ assisted the transformation and offered $95 \% \mathrm{ee}^{39}$, similar to the present catalytic system. To the best of our knowledge, there is no report available on enantioselective reduction reaction catalyzed by Ru-benzene complexes containing aminoacid or aminoacid derived ligands.
The ability of $\mathrm{Ru}(\mathrm{II})$-benzene complexes (1-6) to catalyze the ATH of acetophenone was compared with our previously reported $\mathrm{Ru}$ (II)-benzene catalysts. The present catalysts required $15 \mathrm{~h}$ to exhibit $99 \%$ conversion and $99 \%$ ee. Nevertheless, our previous $\mathrm{Ru}(\mathrm{II})$-benzene catalysts bearing chiral phenylalanine derived aroylthiourea ligands needed only $8 \mathrm{~h}$ for $99 \%$ conversion and $99 \%$ ee. ${ }^{40}$ With chiral amine based aroylthiourea ligands, $\mathrm{Ru}(\mathrm{II})$-benzene catalysts took 14 $\mathrm{h}$ for the same performance. ${ }^{36}$ Though the present $\mathrm{Ru}$ (II)-benzene catalysts wanted more time for excellent conversion and ee, it is to be noted that the reactions were 


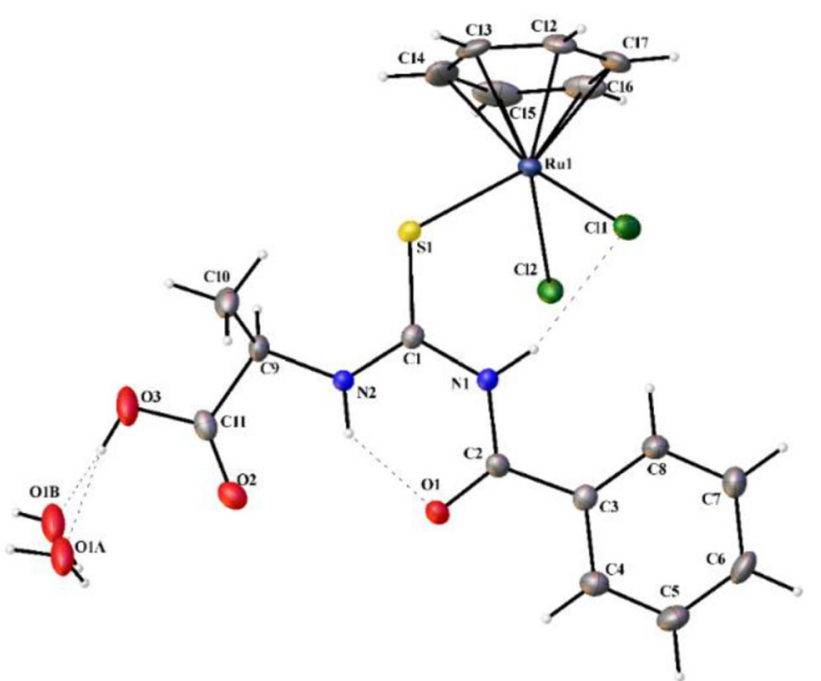

Figure 1. Thermal ellipsoidal plot (50\% probability level) of 1. Selected bond distances $(\AA)$ and angles $\left({ }^{\circ}\right)$ : $\mathrm{Ru}(1)-\mathrm{S}(1)$ 2.4062(9), Ru(1)-Cl(1) 2.4373(10), Ru(1)-Cl(2) 2.4300(10), S(1)-Ru(1)-Cl(1) 93.47(3), S(1)-Ru(1)-Cl(2) 89.91(2), Cl(2)-Ru(1)-Cl(1) 87.88(2) and C(1)-S(1)-Ru(1) 117.18(10).

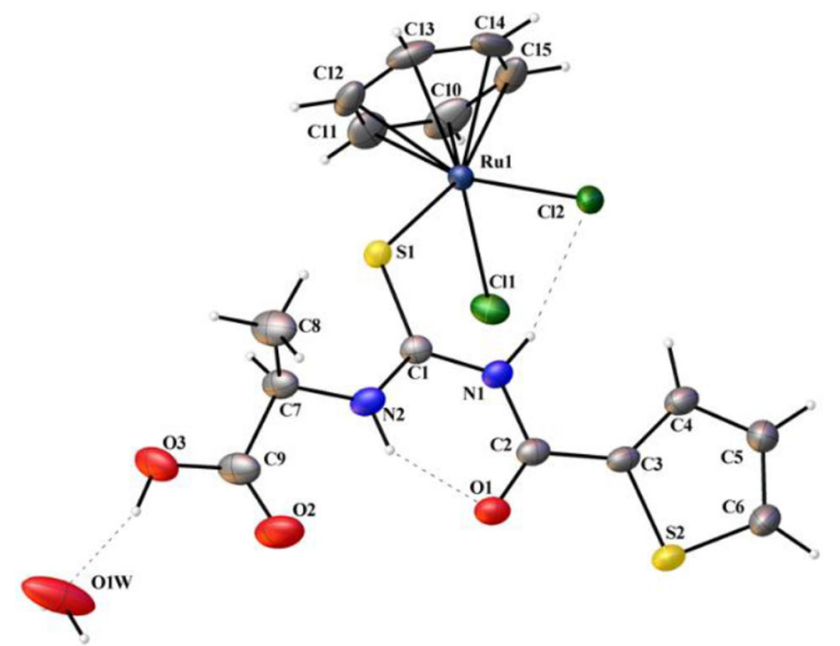

Figure 2. Thermal ellipsoidal plot (50\% probability level) of 3. Selected bond distances $(\AA)$ and angles $\left({ }^{\circ}\right)$ : Ru(1)-S(1) 2.4047(6), Ru(1)-Cl(1) 2.4162(6), Ru(1)-Cl(2) 2.4130(6), $\mathrm{S}(1)-\mathrm{Ru}(1)-\mathrm{Cl}(1) \quad 89.12(2), \quad \mathrm{S}(1)-\mathrm{Ru}(1)-\mathrm{Cl}(2) \quad 92.54(2)$, $\mathrm{Cl}(2)-\mathrm{Ru}(1)-\mathrm{Cl}(1)$ 87.36(2), C(1)-S(1)-Ru(1) 117.08(8).

carried out in water medium whereas in the previous cases the solvent was isopropanol. Further, the comparison was also made with $\mathrm{Ru}(\mathrm{II})-p$-cymene complexes containing the same ligands. The $p$-cymene complexes required $20 \mathrm{~h}$ to exhibit $99 \%$ conversion and $99 \%$ ee whereas $\mathrm{Ru}(\mathrm{II})$-benzene catalysts (1-6) demonstrated the same conversion and ee within $15 \mathrm{~h}$. The enhanced reactivity of the $\mathrm{Ru}$ (II)-benzene complexes compared to the $\mathrm{Ru}(\mathrm{II})-p$-cymene complexes was explained theoretically. ${ }^{36}$

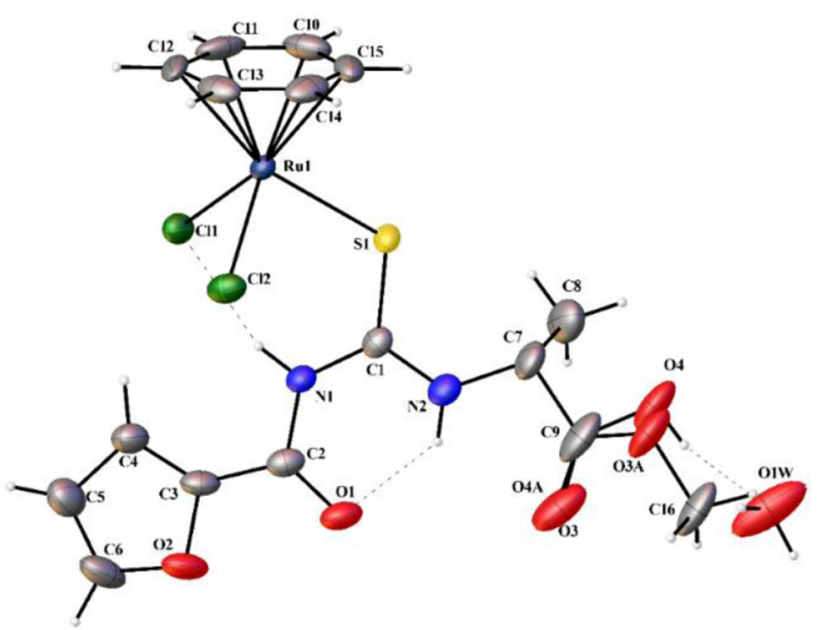

Figure 3. Thermal ellipsoidal plot (50\% probability level) of 5. Selected bond distances (A) and angles $\left(^{\circ}\right): \quad \mathrm{Ru}(1)-\mathrm{S}(1) \quad 2.4082(12), \quad \mathrm{Ru}(1)-\mathrm{Cl}(1) \quad 2.4230(12)$, $\mathrm{Ru}(1)-\mathrm{Cl}(2) \quad 2.4131(12), \quad \mathrm{S}(1)-\mathrm{Ru}(1)-\mathrm{Cl}(1) \quad 92.78(4)$, $\mathrm{S}(1)-\mathrm{Ru}(1)-\mathrm{Cl}(2) \quad 89.35(4), \quad \mathrm{Cl}(2)-\mathrm{Ru}(1)-\mathrm{Cl}(1) \quad 86.46(4)$, C(1)-S(1)-Ru(1) 116.49(14).

Using the optimized conditions, the scope of the system was extended to include more ketones. $R$ tomoxetine is a drug used for the treatment of attention deficit hyperactivity disorder, which is synthesized from 1-(o-tolyl)ethanol. ${ }^{41}$ Catalysts 1-6 were active for enantioselective reduction of 2-methyl acetophenone to yield $(R)-1-(o$-tolyl)ethanol with up to $84 \%$ conversion and $99 \%$ ee (Table 1, entries 7-12). Chiral $\mathrm{Ru}(\mathrm{II})$-benzene complexes (1-6) were used as catalysts for the conversion of 4-fluoro acetophenone to $(R)$ 1-(4-fluorophenyl)ethanol (up to $94 \%$ conversion and $94 \%$ ee) which possesses numerous biological applications (Table 1, entries 13-18). ${ }^{42}$ The enantioselective reduction of 2-acetylfuran to 1-(furan-2-yl)ethanol was attained in our method with up to $98 \%$ conversion and $97 \%$ ee (Table 1, entries 19-24). Chiral benzhydrol is broadly used for the synthesis of many pharmaceuticals. ${ }^{43}$ Using the Ru(II)-benzene catalytic system, the transformation of 4-methoxy benzophenone to (4methoxyphenyl)(phenyl)methanol was achieved with conversion up to $85 \%$ and ee up to $98 \%$ (Table 1, entries 25-30).

\section{Conclusions}

In this article, we have reported the synthesis and complete characterization of the half-sandwich $\mathrm{Ru}(\mathrm{II})$ benzene complexes which were obtained from the reactions between $\left[\mathrm{RuCl}_{2}\left(\eta^{6}-\mathrm{C}_{6} \mathrm{H}_{6}\right)\right]_{2}$ and chiral aroylthiourea ligands. The structure of the complexes was confirmed by single crystal X-ray diffraction study. In all the $\mathrm{Ru}(\mathrm{II})$-benzene complexes, monodentate coordination of aroylthiourea ligand through sulfur atom and the 
unprotected acid group were observed. All the Ru(II)benzene complexes were found to be effective catalysts for the ATH of ketones to their corresponding chiral alcohols in water medium. The conversions and enantiomeric excesses were found to be good to excellent. The present catalytic system operates with an environmentally pleasant and simple procedure without inert condition, which will be very much helpful in industrial synthetic processes.

\section{Supplementary Information (SI)}

CCDC 1829315-1829317. The table of the X-ray crystallographic data, atomic coordinates in CIF format, ${ }^{1} \mathrm{H}$ and ${ }^{13} \mathrm{C}$-NMR spectra of the complexes, GC-MS chromatogram and HPLC chromatograms are included. Supplementary Information is available at www.ias.ac.in/chemsci.

\section{Acknowledgements}

M.M.S. acknowledges the Department of Science and Technology, Ministry of Science and Technology, Government of India, for the doctoral fellowship under DST-INSPIRE scheme.

\section{References}

1. Ohkuma T and Noyori R 2001 Asymmetric catalysis by architectural and functional molecular engineering: practical chemo- and stereoselective hydrogenation of ketones Angew. Chem. Int. Ed. 4040

2. Jacobsen E N, Pfaltz A and Yamamoto H 1999 In Comprehensive Asymmetric Catalysis (Berlin: Springer)

3. Palmer M J and Wills M 1999 Asymmetric transfer hydrogenation of $\mathrm{C}=\mathrm{O}$ and $\mathrm{C}=\mathrm{N}$ bonds Tetrahedron: Asymmetry 102045

4. Li C J and Chan T H 1997 In Organic Reactions in Aqueous Media (New York: John Wiley \& Sons)

5. Lindstrçm U M 2002 Stereoselective organic reactions in water Chem. Rev. 1022751

6. Butler R N and Coyne A G 2010 Water: nature's reaction enforcer-comparative effects for organic synthesis "inwater" and "on-water" Chem. Rev. 1106302

7. Wu X and Xiao J 2007 Aqueous-phase asymmetric transfer hydrogenation of ketones - a greener approach to chiral alcohols Chem. Commun. 2449

8. Wu X, Wang C and Xiao J 2010 Asymmetric transfer hydrogenation in water with platinum group metal catalysts Platinum Met. Rev. 543

9. Bubert C, Blacker J, Brown S M, Crosby J, Fitzjohn S, Muxworthy J P, Thorpe T and Williams J M 2001 Synthesis of water-soluble aminosulfonamide ligands and their application in enantioselective transfer hydrogenation Tetrahedron Lett. 424037

10. Thorpe T, Blacker J, Brown S M, Bubert C, Crosby J, Fitzjohn S, Muxworthy J P and Williams J M 2001 Efficient rhodium and iridium-catalysed asymmetric transfer hydrogenation using water-soluble aminosulfonamide ligands Tetrahedron Lett. 424041
11. Wu X, Li X, Hems W, King F and Xiao J 2004 Accelerated asymmetric transfer hydrogenation of aromatic ketones in water Org. Biomol. Chem. 21818

12. Gladiali S and Alberico E 2006 Asymmetric transfer hydrogenation: chiral ligands and applications Chem. Soc. Rev. 35226

13. Wu X F, Li X H, McConville M, Saidi O and Xiao J L $2006 \beta$-Amino alcohols as ligands for asymmetric transfer hydrogenation of ketones in water J. Mol. Catal. A: Chem. 247153

14. Naota T, Takaya H and Murahashi S I 1998 Rutheniumcatalyzed reactions for organic synthesis Chem. Rev. 98 2599

15. Trost B M, Toste F D and Pinkerton A B 2001 Nonmetathesis ruthenium-catalyzed $\mathrm{C}-\mathrm{C}$ bond formation Chem. Rev. 1012067

16. Peacock A F A and Sadler P J 2008 Medicinal organometallic chemistry: designing metal arene complexes as anticancer agents Chem.-Asian J. 3 1890

17. Kumar P, Gupta R K and Pandey D S 2014 Half-sandwich arene ruthenium complexes: synthetic strategies and relevance in catalysis Chem. Soc. Rev. 43707

18. He Y M and Fan Q H 2015 Advances in transfer hydrogenation of carbonyl compounds in water ChemCatChem. 7398

19. Tombo G M R and Bellus D 1991 Chirality and crop protection Angew. Chem., Int. Ed. 301193

20. Farina V, Reeves J T, Senanayake C H and Song J J 2006 Asymmetric synthesis of active pharmaceutical ingredients Chem. Rev. 1062734

21. Busacca C A, Frandrick D R, Song J J and Senanayake C H 2011 The growing impact of catalysis in the pharmaceutical industry Adv. Synth. Catal. 353 1825

22. Blaser H U, Buser H P, Coers K, Hanreich R, Jallett H $\mathrm{P}$, Jelsch E, Pugin B, Schneider H D, Spingler F and Wegmann A 1999 The chiral switch of metolachlor: the development of a large-scale enantioselective catalytic process Chimia $\mathbf{5 3 2 7 5}$

23. Blaser H U, Spindler F and Studer M 2001 Enantioselective catalysis in fine chemicals production Appl. Catal. A: Gen. 221119

24. Dobbs D A, Vanhessche K P M, Brazi E, Rautenstrauch V, Lenoir J Y, Genet J P, Wiles J and Bergens S H 2000 Industrial synthesis of (+)-cis-methyl dihydrojasmonate by enantioselective catalytic hydrogenation; identification of the precatalyst $\left[\mathrm{Ru}((-)-\mathrm{Me}-\mathrm{DuPHOS})(\mathrm{H})\left(\eta^{6}-\right.\right.$ 1,3,5-cyclooctatriene)]( $\left.\mathrm{BF}_{4}\right)$ Angew. Chem., Int. Ed. 39 1992

25. Marino S T, Stachurska-Buczek D, Huggins D A, Krywult B M, Sheehan C S, Nguyen T, Choi N, Parsons J G, Griffiths P G, James I W, Bray A M, White J M and Boyce R S 2004 Synthesis of chiral building blocks for use in drug discovery Molecules 9405

26. Mary Sheeba M, Muthu Tamizh M, Bhuvanesh N S P and Karvembu R 2018 Water soluble Ru(II)$p$-cymene complexes of chiral aroylthiourea ligands derived from unprotected D/L-alanine as proficient catalysts for asymmetric transfer hydrogenation of ketones Appl. Organometal. Chem. https://doi.org/10.1002/aoc. 4667 
27. Bennett M A and Smith A K 1974 Arene ruthenium(II) complexes formed by dehydrogenation of cyclohexadienes with ruthenium(III) trichloride J. Chem. Soc. Dalton Trans. 233

28. APEX2 "Program for data collection on area detectors" BRUKER AXS Inc., 5465 East Cheryl Parkway, Madison, WI 53711-5373 USA.

29. SADABS Sheldrick G M "Program for absorption correction of area detector frames", BRUKER AXS Inc., 5465 East Cheryl Parkway, Madison, WI 53711-5373 USA.

30. Sheldrick G M 2015 SHELXT - Integrated space-group and crystal-structure determination Acta Cryst. A71 3

31. Sheldrick G 2008 M A short history of SHELX Acta Cryst. A64 112

32. Spek A L 2003 Single-crystal structure validation with the program PLATON J. Appl. Cryst. 367

33. Dolomanov O V, Bourhis L J, Gildea R J, Howard J A K and Puschmann H 2009 OLEX2: a complete structure solution, refinement and analysis program J. Appl. Cryst. 42339

34. Sheeba M M, Tamizh M M, Farrugia, L J, Endo A and Karvembu R 2014 Chiral ( $\eta^{6}-p$-cymene)ruthenium(II) complexes containing monodentate acylthiourea ligands for efficient asymmetric transfer hydrogenation of ketones Organometallics $\mathbf{3 3} 540$

35. Grabulosa A, Mannua A, Alberico E, Denurra S, Gladiali $S$ and Muller G 2012 Neutral $\eta^{6}$-arene ruthenium complexes with monodentate P-donor ligands: activation in the transfer hydrogenation reaction J. Mol. Catal. A: Chem. 363-364 49

36. Mary Sheeba M, Preethi S, Nijamudheen A, Muthu Tamizh M, Datta A, Farrugia L J and Karvembu R 2015 Half-sandwich $\mathrm{Ru}\left(\eta^{6}-\mathrm{C}_{6} \mathrm{H}_{6}\right)$ complexes with chiral aroylthioureas for enhanced asymmetric transfer hydrogenation of ketones-experimental and theoretical studies Catal. Sci. Technol. 54790

37. Canivet J, Labat G, Stoeckli-Evans H and Süss-Fink G 2005 Water-soluble arene ruthenium complexes containing a trans-1,2-diaminocyclohexane ligand as enantioselective transfer hydrogenation catalysts in aqueous solution Eur. J. Inorg. Chem. 4493

38. Matsunaga H, Ishizuka T and Kunieda T 2005 Highly efficient asymmetric transfer hydrogenation of ketones catalyzed by chiral 'roofed' cis-diamine-Ru(II) complex Tetrahedron Lett. 463645

39. Wettergren J, Buitrago E, Ryberg P and Adolfsson H 2009 Mechanistic investigations into the asymmetric transfer hydrogenation of ketones catalyzed by pseudodipeptide ruthenium complexes Chem. Eur. J. 155709

40. Mary Sheeba M, Muthu Tamizh M, Farrugia L J and Karvembu R 2017 Asymmetric hydrogenation of pro-chiral ketones catalyzed by chiral $\mathrm{Ru}(\mathrm{II})$-benzene organometallic compounds containing amino acid based aroylthiourea ligands J. Organomet. Chem. 83145

41. Srebnik M, Ramachandran PV and Brown H C 1988 Chiral synthesis via organoboranes. 18 . Selective reductions. 43. Diisopinocampheylchloroborane as an excellent chiral reducing reagent for the synthesis of halo alcohols of high enantiomeric purity. A highly enantioselective synthesis of both optical isomers of Tomoxetine, Fluoxetine, and Nisoxetine J. Org. Chem. 532916

42. Zhang X J, Lai T B and Kong R Y C 2011 Biology of fluoro-organic compounds Top. Curr. Chem. 308365

43. Wu J, Ji J X and Chan A S C 2005 A remarkably effective copper(II)-dipyridylphosphine catalyst system for the asymmetric hydrosilylation of ketones in air Proc. Natl. Acad. Sci. 1023570 